\title{
The role of immunohistochemistry in the detection of vascular invasion in specimens of endoscopic submucosal dissection
}

\author{
o papel da imuno-bistoquímica na detecção de invasão \\ vascular em espécimes de dissecção endoscópica da submucosa
}

Nayze Lucena Sangreman Aldeman ${ }^{1}$; Daniel Moore Freitas Palhares²; Stanley Almeida Araújo3;

Moisés Salgado Pedrosa $a^{4}$ : Luísa Lima Castro² ${ }^{2}$ Vitor Nunes Arantes ${ }^{5}$ : Mônica Maria Demas Álvares Cabral ${ }^{6}$

\begin{abstract}
Introduction: Endoscopic submucosal dissection (ESD) of early neoplasias of the gastrointestinal tract (GIT) has been increasingly applied as an alternative to invasive surgical procedures, with the aim to preserve the patient's organ and quality of life, although it does not allow the histopathological analysis of lymph nodes. Previous studies demonstrated that the presence of neoplastic emboli in lymphatic (lymphatic vascular invasion [LVI]) or blood vessels (blood vascular invasion [BVI]) is considered a positive predictive factor for the occurrence of lymph node metastasis. The assessment of vascular invasion carried out only by routine hematoxylin and eosin staining (HE) may yield both falsepositive and false-negative results. D2-40 is a specific monoclonal antibody to the lymphatic endothelium. Thus, it is useful for identifying LVI and distinguishing if tumor embolization is found in blood or lymphatic vessels. Objective: To determine the role of immunohistochemistry (IHC) in the assessment of ESD specimens by comparing the detection of LVI and BVI by HE and IHC with D2-40 and CD34 immunolabeling. Method: We conducted the IHC study using D2-40 and CD34 markers (pan-endothelial) in 30 cases of ESD with histological diagnosis of carcinoma in order to assess the presence of LVI and BVI. Results: The detection of LVI was more prevalent than BVI. Three out of six cases with LVI were false-positive by HE and six were false-negative by IHC. Regarding BVI, five cases were identified and one was false-negative by IHC. Conclusion: Our results indicated that the histopathological analysis of ESD specimens by exclusively routine HE staining does not allow proper evaluation of BVI or LVI.
\end{abstract}

Key words: endoscopic submucosal dissection; lymphatic vascular invasion; blood vascular invasion; CD34; D2-40.

\section{INTRODUCTION}

The endoscopic resection of neoplasms of the gastrointestinal tract (GIT) has been accepted as an alternative to surgery in selected cases $^{(4)}$. The technique of endoscopic submucosal dissection (ESD) was developed in Japan in order to enable en bloc resection of neoplastic lesions larger than $2 \mathrm{~cm}$. A major advantage of DES is to produce an adequate sample for histological assessment ${ }^{(10,11)}$.
Nevertheless, endoscopic resection, obviously, does not allow the removal or histopathological evaluation of locoregional lymph nodes. In general, in these cases, lymph node staging is performed with imaging methods such as computed tomography ${ }^{(5)}$.

Regarding the risk of lymph node metastasis, previous studies demonstrated that the presence of neoplastic vascular emboli, either in lymphatic (lymphatic vascular invasion [LVI]) or in blood vessels (blood vascular invasion [SVI]), is deemed to

First submission on $22 / 04 / 13$; last submission on 16/06/13; accepted for publication on 17/06/13; published on 20/08/13

1. Master's in Pathology by Universidade Federal de Minas Gerais (UFMG); pathologist at LAPAC.

2. Graduate student in Medicine at UFMG.

3. Master's in Infectology and Tropical Medicine by UFMG; professor at Universidade Federal de Ouro Preto (UFOP)

4. Pathologist at Centro de Estudos em Anatomia e Patologia (CEAP).

5. Doctor in Health Sciences by UFMG; adjunct professor at UFMG.

6. Doctor in Pathology by UFMG; adjunct professor at the Anatomy Pathology and Legal Medicine Department-UFMG. 
be a positive predictive factor for the occurrence of lymph node metastasis ${ }^{(6)}$. Therefore, since lymphadenectomy is not performed during the endoscopic resection, the presence of LVI or BVI in ESD specimens should be carefully considered.

Currently, LVI and BVI are evaluated by routine hematoxylin and eosin staining $(\mathrm{HE})^{(3)}$. Such assessment, however, may be carried out with greater accuracy by adding immunohistochemical markers (IHC) to the vascular endothelium of blood (CD34) and lymphatic vessels $(\mathrm{D} 2-40)^{(2,7)}$.

\section{OBJECTIVE}

The aim of this study was to compare the detection of LVI and BVI by using CD34 and D2-40 IHC markers and the analysis of histological pattern by HE in DES specimens.

\section{METHOD}

It is a cross-sectional study of a series of specimens obtained through DES from 30 patients with GIT neoplasias, who underwent this procedure at the Endoscopy Service of Instituto Alfa de Gastroenterologia, Universidade Federal de Minas Gerais-Clinical Hospital (UFMG-CH) during the period of 2008 to 2012. The study was approved by the Research and Ethics Committee of UFMG. By the end of DES, the specimen was carefully recovered with a foreign body extractor. Initially, it was kept in saline solution for several minutes. Subsequently, the piece was stretched and fixed on a cork board, photographed, immersed in a solution of $10 \%$ formalin and sent to the pathology department. The specimen was coated with India ink on the deep margin and $2 \mathrm{~mm}$ serial sections were performed. All the material was embedded in paraffin blocks, enabling the suitable histopathological analysis of the entire specimen.

The general features of the primary tumor analyzed by $\mathrm{HE}$ were the following: histological classification of the tumor according to World Health Organization (WHO), histological differentiation grade, type classification, lateral and deep margins, BVI and LVI and depth of the tumor.

For IHc assessment, we chose the paraffin blocks that best represented deep tumor invasion. From selected paraffin blocks, serial $4 \mathrm{~mm}$ histological sections were performed and, subsequently, placed on silanized slides. Monoclonal antibodies were applied: D2-40 (clone D2-40, Dako) and CD34 (clone QBAND/10, Biogenex). The IHC technique was amplified polymer according to the method recommended by the Immunohistochemistry Manual from the Brazilian Society of Pathology (SBP) and the slides were processed with diaminobenzidine (DAB). The background staining was performed with hematoxylin. Negative controls consisted in the replacement of primary antisera for rabbit or goat immunoglobulins of the same primary antibody class.

The presence of BVI or LVI by HE staining was considered positive only when a neoplastic cell embolus was clearly visualized within the vascular lumen lined by clear endothelium. The BVI was defined by the presence of erythrocytes and neoplastic emboli on the vascular lumen, with or without smooth muscle surrounding the endothelium positively stained for CD34. The BVI was identified when the immunohistochemistry was negative for D2-40 and positive for $\mathrm{CD} 34$, associated with the presence of erythrocytes in the vascular lumen. For the definition of LVI, neoplastic emboli should be surrounded by endothelium, positively stained for D2-40 and without erythrocytes or smooth muscle.

The investigation database and all statistical calculations were carried out with the following statistical program: Statistical Package for Social Science for Windows (SPSS) 17.0 (SPSS, Inc, Chicago, III). The $p$ value $<0.05$ was considered statistically significant. Cohen's Kappa coefficient was deployed to verify if the agreement between different methods of vascular invasion assessment (HE and IHC) was purely random variation. Chi-square test was applied to analyze the association between categorical variables such as the presence of BVI or LVI and depth of the tumor.

\section{RESULTS}

\section{General characteristics of the sample}

All patients (30) underwent endoscopic submucosal dissection. Table 1 shows the clinicopathological characteristics of the sample.

\section{Assessment of LVI and BVI}

The detection of LVI was considerably higher in comparison with BVI. The presence of LVI was detected in six out of 30 cases (20\%) by HE and in nine out of 30 cases (30\%) by IHC. The BVI was detected in five out of 30 cases (16.7\%) by HE and in only one case by IHC (3.3\%).

\section{Comparison of the effectiveness of HE and IHC methods in identifying vascular invasion}

The comparison between the detection of vascular invasion by HE staining methods and IHC presented some differences. 
Concerning LVI, there was no statistically significant difference between the values $(p=0.232)$. The presence of BVI detected by IHC was lower in comparison with HE $(p=0.272)$. Kappa coefficient for the diagnostic agreement between both methods was weak for LVI (Kappa $=0.211)$ and poor for BVI (Kappa $=$ 0.167), as shown in Table 2.

TABLE 1 - Clinicopathological features of the sample

\begin{tabular}{|c|c|}
\hline Clinicopathological data & $n=30(100 \%)$ \\
\hline \multicolumn{2}{|c|}{ Gender } \\
\hline Male & $19(63.3)$ \\
\hline Female & $11(36.7)$ \\
\hline \multicolumn{2}{|c|}{ Topography } \\
\hline Esophagus & $18(60)$ \\
\hline Stomach & $8(26.7)$ \\
\hline Rectum & $2(6.7)$ \\
\hline Colon & $2(6.7)$ \\
\hline \multicolumn{2}{|c|}{ WHO histological type } \\
\hline Squamous cell carcinoma & $16(53.3)$ \\
\hline Adenocarcinoma & $13(43.3)$ \\
\hline Signet ring cell carcinoma & $1(3.3)$ \\
\hline \multicolumn{2}{|c|}{ Depth of invasion } \\
\hline M1 & $8(26.7)$ \\
\hline M2 & $8(26.7)$ \\
\hline M3 & $9(30.0)$ \\
\hline SM1 & $4(13.3)$ \\
\hline SM2 & $1(3.3)$ \\
\hline \multicolumn{2}{|c|}{ Grade of differentiation } \\
\hline Well differentiated & $5(16.7)$ \\
\hline Moderately differentiated & $25(83.3)$ \\
\hline Poorly differentiated & $0(0)$ \\
\hline
\end{tabular}

WHO: World Health Organization.

TABLE 2 - Comparison of diagnostic agreement in the detection of LVI and BVI by HE and IHC

\begin{tabular}{ccccc}
\hline Parameters & $\begin{array}{c}\text { HE } \\
\text { assessment }\end{array}$ & $\begin{array}{c}\text { IHC } \\
\text { assessment }\end{array}$ & $p$ value & Kappa \\
\hline Presence of LVI & 6 & 9 & 0,232 & 0,211 \\
Absence of LVI & 24 & 21 & & \\
Presence of BVI & 5 & 1 & 0,272 & 0,167 \\
Absence of BVI & 25 & 29 & & \\
\hline
\end{tabular}

LVI: lymphatic vascular invasion; BVI: blood vascular invasion; HE: hematoxylin and eosin; IHC: immunobistochemistry.

Three (50\%) out of six cases with LVI detected by HE were not confirmed by IHC. In contrast, we observed LVI by IHC in six of them ( $25 \%$ of negative cases), which had not previously been detected by HE.

Some examples of LVI not detected by conventional histopathological examination (HE) are shown in Figure as well as a case in which LVI detected by HE was not confirmed by immunohistochemical examination.
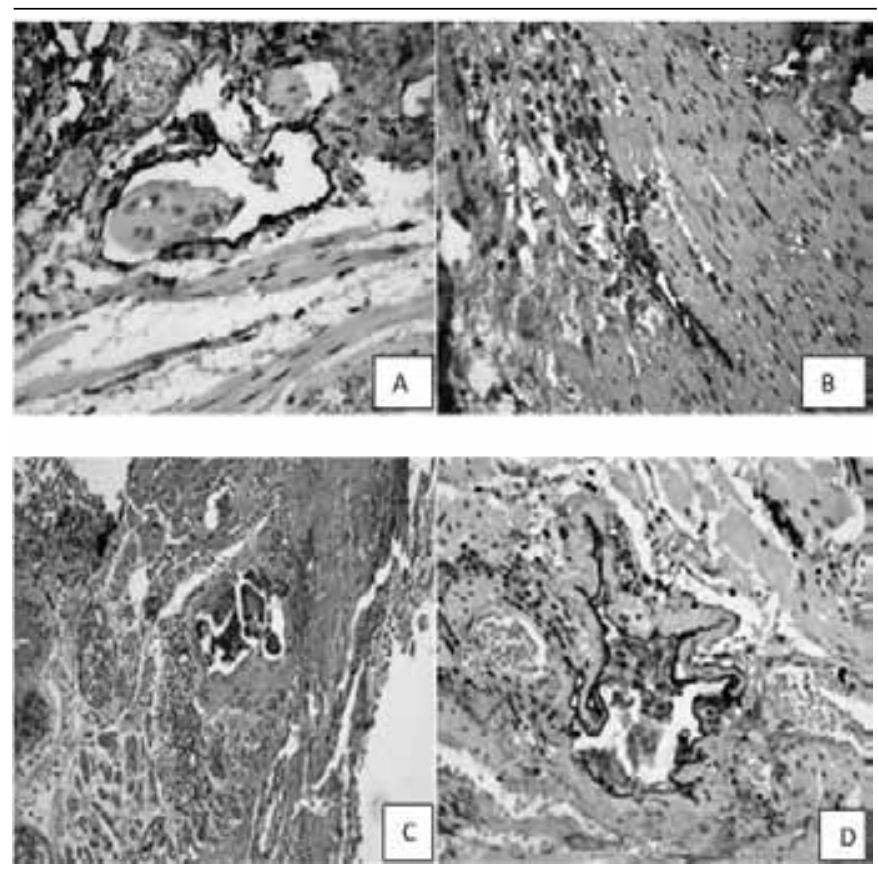

FIGURE - Photomicrographs of LVI detected only by IHC and false vascular invasion diagnosed by HE A and B: LVI (immunostaining by D2 dial-40 [400×]), C: false LVI (HE, $400 \times$ ); D: false LVI (immunostaining by D2 dial-40 [400×])

LVI: lymphatic vascular invasion; IHC: immunohistochemistry; HE: hematoxylin and eosin

\section{Correlation between clinicopathological variables and LVI and BVI detected by IHC}

When we analyze LVI detected by immunohistochemical examination, we may identify a statistically significant relation with the depth of the tumor in layers $\mathrm{m} 1(p=0.031)$ and $\mathrm{m} 3$ $(p=0.047$ ), when compared with other levels of tumor depth.

There was no significant correlation between the presence of LVI and the following variables: gender, topography, histological type of tumor and degree of differentiation. As to BVI, all variables demonstrated no correlation with the presence of BVI.

\section{DISCUSSION}

Endoscopic submucosal dissection (ESD) is increasingly deployed in the management of early neoplasias of the gastrointestinal tract. Furthermore, it produces a high-quality 
sample, allowing a proper pathological evaluation and reliable information on the neoplasia, such as size, histological grade, type of differentiation, depth of invasion, presence of neoplastic cell emboli in blood and lymphatic vessels and the status of surgical resection margins.

The evaluation of these factors allows a more precise diagnosis and $\mathrm{T}$ staging of the neoplastic lesion. Moreover, it permits to determine the prognosis and the need for additional procedures.

In the present study, we investigated if the addition of IHC with specific markers (D2-40 and CD34) for standard histopathological evaluation with HE staining affects the detection of LVI and BVI. The yielded results revealed that detection of LVI by HE staining was higher, although not statistically different $(p=0.232)$, in comparison with IHC. The presence of LVI was detected in six cases by HE and nine by IHC. Among six cases of LVI observed by HE staining, only three were confirmed by IHC, suggesting that there were false-positive results in three cases. Furthermore, IHC allowed the detection of LVI in six patients, which may have gone unnoticed by $\mathrm{HE}$ staining. These results generated a low coefficient of agreement (kappa $=0.211$ ) between $\mathrm{HE}$ and IHC analysis. This difference was corroborated by other studies that underline the importance of IHC analysis of vascular invasion in advanced neoplasias $^{(1,3,8,11)}$.

It is worth highlighting that histopathological analysis of slides stained with $\mathrm{HE}$ with the aim to detect LVI is prone to these inaccuracies. By using only this routine staining, pathologists may not be able to differentiate retraction artifacts around cell groups or neoplastic glands from real vascular invasion. Cases in which the neoplastic emboli totally fill the vascular lumen are also hindered, inasmuch as their identification without specific immunostaining of the lymphatic endothelium is precluded. Moreover, falsepositive results for LVI may occur when the presence of BVI is misinterpreted as LVI by HE staining. These discrepancies were also observed in other series of studies, mainly focusing on gastric carcinomas $^{(1,11)}$.

As to the assessment of BVI in histological sections stained by routine HE, we obtained five positive cases. Nevertheless, IHC did not confirm the positivity observed by HE in any of them. Therefore, these five cases correspond to false-positive results for BVI by HE. In contrast, when subjected to IHC, we identified one positive case for BVI among 25 cases considered negative for BVI by conventional HE, thus demonstrating a false-negative case by HE. Despite the apparent discrepancy between $\mathrm{HE}$ and IHC findings, there was no statistically significant difference $(p=0.272)$ in six cases $(20 \%)$ of the sample. This bias could be attributed to the fact that some among these cases may have been misinterpreted as BVI instead of LVI or they may be tissue retraction surrounding neoplastic cells in $\mathrm{HE}$ assessment, inasmuch as this staining does not allow the proper distinction between these factors in all cases ${ }^{(9)}$.

The analysis of tumor invasion depth on the organ walls revealed that most early GIT neoplasias investigated in this study were intramucosal tumors (83.3\%) and superficial submucosal (13.3\%), hence demonstrating that almost all cases met the criteria established for the indication of SED. Only one case (3.4\%) reached the middle third of the submucosal layer (sm2), which was evidenced only histologically. It is worth noting that there was a significant correlation between the depth of tumor invasion ( $\mathrm{ml}$ and $\mathrm{m} 3)$ and the presence of $\mathrm{LVI}(\phi=0.031$ and $p=0.047)$ herein.

In general, it is believed that in cases of early carcinomas there is less likelihood of neoplastic invasion into blood and lymphatic vessels. However, studies on the density of lymphatic network on the wall of the GIT organs, particularly in the normal gastric wall, attest that the concentration of lymph vessels is considerably higher in the muscular mucosa layer, which may be infiltrated in the so-called early neoplasias ${ }^{(8)}$. These studies corroborate the statistically significant results obtained through the correlation of depth of tumor invasion and LVI in $\mathrm{m} 3$ layer.

A statistically significant correlation between depth of tumor invasion in layer $\mathrm{m} 1$ and LVI is due to the fact that there were no positive cases of LVI insofar as they are neoplasias restricted to the epithelium (in situ).

\section{CONCLUSION}

In conclusion, LVI and BVI are parameters to be systematically analyzed in histopathology due to its considerable prognostic value, determining the choice of complementary therapy after SED. Accordingly, they should be evaluated by more sensitive and specific methods and incorporated into the protocol of routine histopathological examination.

Our results demonstrate that IHC method using the combined markers (CD34 and D2-40) is superior in detecting LVI and BVI when compared with routine HE staining, which may be of great value in clinical practice in order to optimize the accuracy of pathological staging of early endoscopically resected neoplasias. 


\section{RESUMO}

Introdução: A dissecção endoscópica da submucosa (DES) de neoplasias precoces do trato gastrointestinal (TGI) tem sido cada vez mais aplicada como alternativa aos procedimentos cirúrgicos invasivos, visando a preservar o órgão e a qualidade de vida do paciente, contudo, não possibilita a avaliação bistopatológica de linfonodos. Estudos anteriores demonstraram que a presença de êmbolos neoplásicos, em vasos linfáticos (invasão vascular linfática [IVL]) ou sanguíneos (invasão vascular sanguinea [IVS]), é considerada um fator preditivo positivo para ocorrência de metástase linfonodal. A avaliação da invasão vascular realizada apenas pela coloração de rotina hematoxilina e eosina (HE) pode gerar resultados falso-positivos e falso-negativos. 0 D2-40 é um anticorpo monoclonal específico para endotélio linfático, sendo, portanto, útil para identificar IVL e distinguir se a embolização tumoral encontra-se em vasos sanguíneos ou linfáticos. Objetivo: Determinar o papel do estudo imuno-histoquímico (IHQ) na avaliação de espécimes de DES, comparando a detecção de IVL e IVS, pelo HE e IHQ com marcação por D2-40 e CD34. Método: Foi realizado estudo IHQ utilizando os marcadores D2-40 e CD34 (pan-endotelial) em 30 casos de produtos de DES com diagnóstico bistológico de carcinoma para avaliar a presença de IVL e IVS. Resultados: A detecção de IVL foi maior que a de IVS. Dos seis casos com IVL ao HE, três eram falso-positivos e seis, falso-negativos à IHQ. Em relação à IVS, foram identificados cinco casos falsopositivos e um falso-negativo à IHQ. Conclusão: Nossos resultados indicaram que a análise bistopatológica dos produtos de DES realizando apenas a coloração HE não permite a avaliação adequada da presença de IVS ou IVL.

Unitermos: dissecção endoscópica da submucosa; invasão vascular sanguínea; invasão vascular linfática; CD34; D2-40.

\section{REFERENCES}

1. ARIGAMI, T. et al. Lymphatic invasion using D2-40 monoclonal antibody and its relationship to lymph node micrometastasis in pN0 gastric cancer. Br J Cancer, v. 93, p. 688-93, 2005.

2. DU, J. R. et al. Vascular endothelial growth factor and microvascular density in esophageal and gastriccarcinomas. World J Gastroenterol, v. 9, n. 7, p. 1604-6, 2003.

3. GRESTA, L. T. Análise comparativa da eficácia do método imunobistoquímico (D2-40 e CD34) e da coloração de rotina (HE) para detecção de invasão vascular linfática e sanguínea no carcinoma gástrico: correlação com outros indicadores prognósticos. 2010. Dissertação (Mestrado em Patologia) - Universidade Federal de Minas Gerais, Belo Horizonte, 2010.

4. LI, C. et al. Risk factors for lymph node metastasis in undifferentiated early gastric cancer. Ann of Surg Oncol, v. 15, p. 764-9, 2007.

5. MITSUHIR0, F. Perspective on the practical indications of endoscopic submucosal dissection of gastrointestinal neoplasm. World J Gastroenterol, v. 27, p. 4289-95, 2008.
6. PANTEL, K.; BRAKENHOFF, R. Dissection the metastatic cascade. Nat Ver Cancer, v. 4, n. 6, p. 448-56, 2004.

7. PRADEEP, C. R.; SUNILA, E. S.; KUTTAN, G. Expression of vascular endothelial growth factor (VEGF) and VEGF receptors in tumor angiogenesis and malignancies. Integr Cancer Ther, v. 4, n. 4, p. 315-21, 2005.

8. SAKO, A. et al. Impact of immunohistochemically identified lymphatic invasion on nodal metastasis in early gastric cancer. Gastric Cancer, v. 9, p. 295-302, 2006

9. VAN DER AUERA, I. et al. First international consensus on the methodology of lymphangiogenesis quantification in solid human tumours. Br J Cancer, v. 95, p. 1611-25, 2006.

10. WEIDNER, N. et al. Tumor angiogenesis and metastasis correlation in invasive breast carcinoma. $N$ Engl J Med, v. 324, n. 1, p. 1-8, 1991.

11. YONEMURA, Y. et al. Evaluation of lymphatic invasion in primary gastric cancer by a new monoclonal antibody, D2-40. Hum Pathol, v. 37, p. $1193-9,2006$

\section{MAILING ADDRESS}

Nayze Lucena Sangreman Aldeman

Rua Doutor Area Leão, 1994, apto 203, bloco C; Vila Operária; CEP: 64002-410; Teresina-PI, Brasil; e-mail: nayzealdeman@ hotmail.com. 